\title{
Eine 52-jährige Patientin mit Abgeschlagenheit und allgemeiner Schwäche
}

\section{A 52-Year-Old Patient with Abnormal Fatigue and Generalized Weakness}

Autor

M. Dafotakis

Institut

Neurologische Klinik, Universitätsklinik, RWTH Aachen
Bibliografie

DOI https://doi.org/10.1055/a-0750-2355

Dtsch Med Wochenschr 2019; 144: 1109-1110

(c) Georg Thieme Verlag KG, Stuttgart · New York

ISSN 0012-0472

\section{Korrespondenzadresse}

Priv.-Doz. Dr. M. Dafotakis

Neurologische Klinik, Universitätsklinik der RWTH Aachen, Pauwelsstraße 30, 52074 Aachen

mdafotakis@ukaachen.de

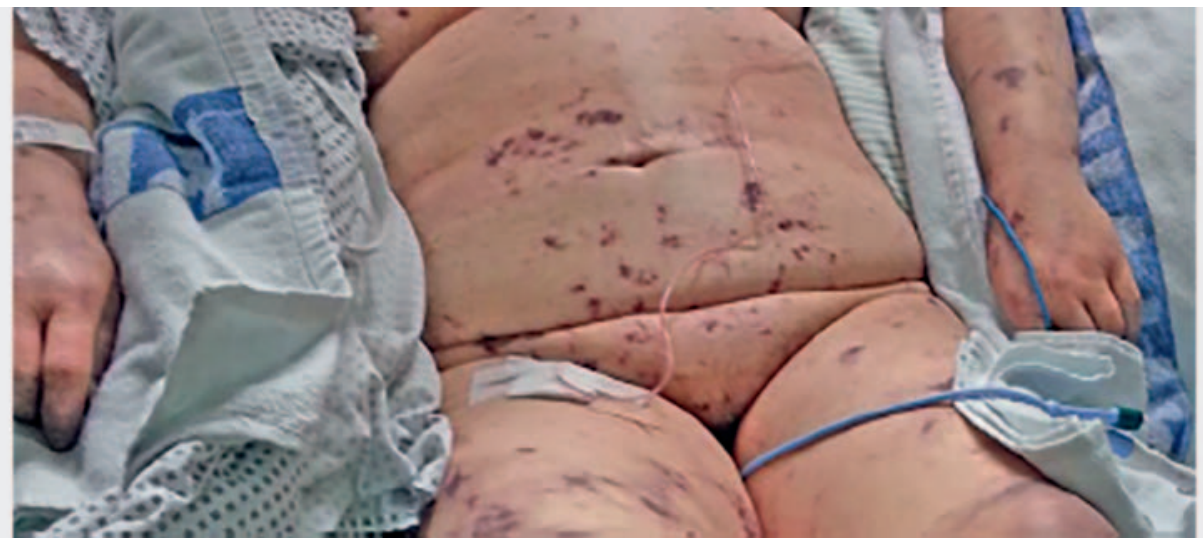

- Abb. 1 Die 52-jährige Patientin am 1. Tag nach stationärer Aufnahme.

Die 52-jährige Patientin stellte sich mit allgemeiner Schwäche und Abgeschlagenheit in der Notaufnahme vor. Seit dem Vortag bestanden ein allgemeines Krankheitsgefühl, Unterbauchbeschwerden und ein Brennen beim Wasserlassen sowie „leichte“ Kopfschmerzen und Fieber bis $39,8^{\circ} \mathrm{C}$. Bei der klinischen Untersuchung war die Patientin somnolent und psychomotorisch verlangsamt. Brudzinski-, Kernig- und Lasègue-Zeichen waren negativ, ebenso der übrige neurologische Befund. Die Laboruntersuchung ergab eine Leukozytose

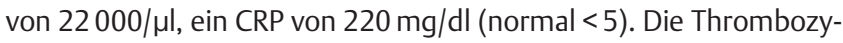
tenzahl betrug $55000 / \mu l$, der INR 1,5. Der D-Dimer-Wert lag bei $3500 \mathrm{ng} / \mathrm{ml}$ (normal <500). Die Lumbalpunktion erbrachte eine leichte Pleozytose von 50 Zellen/ $\mu$ bei sonst unauffälligem Status. Die initiale körperliche Untersuchung zeigt 2 Befunde ( $\triangleright$ Abb. 1).

\section{FRAGEN}

- Welche sind das?

- Erlauben diese Befunde eine Diagnose? Wenn ja, welche?

- Sind Differenzialdiagnosen möglich? Wenn ja, welche? 


\section{Eine 52-jährige Patientin mit Abgeschlagenheit und allgemeiner Schwäche}

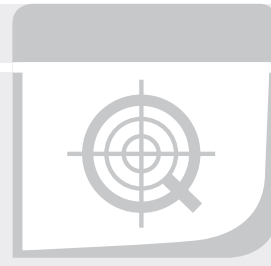

A 52-Year-Old Patient with Abnormal Fatigue and Generalized Weakness

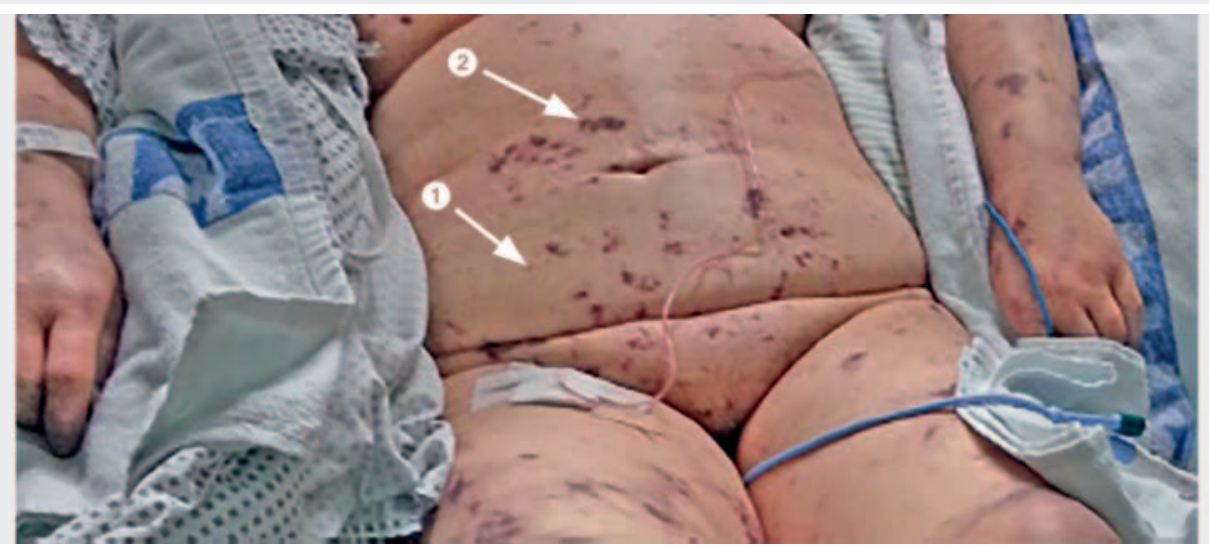

- Abb.2 Die 52-jährige Patientin am 1. Tag nach stationärer Aufnahme.

\section{Befunde}

\section{Petechien}

2. Sugillationen

\section{Diagnose}

- Disseminierte intravasale Gerinnungsstörung aufgrund einer Meningokokkensepsis.

\section{Differenzialdiagnose}

Neben der Meningokokkensepsis kommen andere, v. a. durch gramnegative Bakterien ausgelöste Septitiden infrage.

\section{Erläuterung}

Bei unserer Patientin konnte die Diagnose einer Meningokokkenmeningitis anhand einer positiven Blutkultur gestellt werden. Die initiale Lumbalpunktion hatte lediglich eine leichte Pleozytose von 50 Zellen/ $\mu$ l bei sonst unauffälligem Status erbracht. Erst die Verlaufspunktion einen Tag später erbrachte die typische Konstellation einer bakteriellen Meningitis (6000 Zellen, Laktat $10 \mathrm{mmol} / \mathrm{l}$, Glukose $4 \mathrm{mg} / \mathrm{dl}$, Protein $6,32 \mathrm{~g} / \mathrm{l}$ ). Die Patientin erhielt über 14 Tage Ceftriaxon und konnte nach 3 Wochen mit ambulanter Rehabilitation nach Hause entlassen werden.

Ungewöhnlich an diesem Fall ist die initiale klinische Präsentation. Die Patientin war lediglich leicht somnolent, und die typischen klinischen Meningismus-Zeichen waren allesamt negativ. Nur die psychomotorische Verlangsamung wies auf eine mögliche Beteiligung des ZNS hin, welche sich jedoch auch regelhaft bei Sepsis-Patienten im Rahmen einer septischen Enzephalopathie nachweisen lässt, sodass der initiale Liquorbefund als Begleitmeningitis gewertet wurde.

Die klassische Trias einer Meningokokkenmeningitis besteht aus Kopfschmerzen, Fieber und einem Meningismus. In großen Kollektiven findet sich diese Trias jedoch nur bei ca. $50 \%$ aller Patienten [1]. Erweitert man das klinische Spektrum jedoch um das Symptom Bewusstseinsstörung, so weisen ca. 95 \% aller Patienten zumindest 2 der 4 klinischen Symptome auf [2]. Ein Exanthem bzw. Petechien oder auch Sugillationen finden sich bei der Hälfte der Patienten und kommt fast ausschließlich bei der Meningokokkensepsis vor.

Der vorliegende Fall demonstriert eindrücklich, dass die Diagnose einer Meningokokkenmeningitis neben der klassischen Klinik und dem laborchemischen Befund einer Sepsis immer auch die Untersuchung des gesamten Integuments beinhalten sollte. Eine antibiotische Therapie muss unmittelbar bei $\mathrm{V}$. a. eine Meningokokkenmeningitis initiiert werden.

\section{Erstveröffentlichung}

Dieser Beitrag ist eine aktualisierte Version des Artikels: Dafotakis M. Eine 52-jährige Patientin mit Abgeschlagenheit und allgemeiner Schwäche. Klin Neurophysiol 2016; 47: 85 - 86. doi:10.1055/s-0041-107754.

Literatur

[1] Kuhn J, Gerbershagen K, Mennel HD et al. Cli-nical implications of meningococcal disease. Dtsch Med Wochenschr 2006; 131: 209-213

[2] Durand ML, Calderwood SB, Weber D] et al. Acute bacterial meningitis in adults. A review of 493 episodes. N Engl J Med 1993; 328: 21 - 28 